\title{
COMPUTERIZED EXPERIMENTAL STUDY OF THE EMISSION CHARACTERISTICS OF A HOT SURFACE IGNITION ENGINE, BY USING SUITABLE ALTERNATIVE FUELS WITH ADDITIVES
}

\author{
Nireekshanaraju V1, Durga Prasad B² \\ ${ }^{1}$ Quba College of Engineering and Technology, Andrapradesh, India \\ 2Jawaharlal Nehru Technological University Ananthapur, AndraPradesh, India \\ Email : nireekshana2001@gmail.com
}

\section{Abstract}

The concept of using alternative fuels with palm oil with ethyl ester blends as supplement to diesel engine is recent experimental one. The scarcity of transportation petroleum fuels due to the fast depletion of the petroleum deposits and frequent rise in their costs in the international market have spurred many efforts to find alternatives. The above selected blends were quickly recognized as one among the prime candidates to displace or replace high octane / cetane petroleum fuels like petrol/diesel. The suitable alternative fuels with ethyl ester and its blends is one of the resources, which is both renewable and biodegradable, there fore using these fuels with methyl ester is causing the fuel injectors as clogging effect especially when in cold conditions there for the selected alternative fuels with its blends should be chemically enriched and make the fuel in to an enhanced properties and it becomes to a biodiesel. In this work an attempt has been made to know the performance and emission characteristics of palm oil ethyl ester and of ethanol or methanol with methyl ester blends and its $25 \%$ etc blend with diesel on a direct injection hot surface ignition diesel engine. In this, the ceramic material hot surface ignition method was erupted B A ceramic material is weld inside the top portion of the cylinder chamber. It is connected to the electric circuit ,so that the ceramic surface becomes the red hot surface to ignite the fuel mixture. In this engine the ignition will be occurred by the hot surface in the cylinder, due to the red hot condition of the hot surface the ignition of the blended fuel burns and combustion takes place and thereby the emission of the effluents takes place. Then observing the engine performance on characteristics like BHP, IHP, Indicated thermal efficiency, Break thermal efficiency, specific fuel consumption and the total fuel consumption, exhaust emissions like $\mathrm{HC}, \mathrm{CO}, \mathrm{NO}, \mathrm{NO}_{2}$, smoke emissions, particulate emission. This experiment will be conducted with different blends with $25 \%$ etc diesel and conduct the emission analysis by the analyzer; all these results were carried out on a computerized kirloskar single cylinder direct injection hot surface ignition engine. The performance of the same as compared to the diesel fuel and also found that NOx and emissions are quite higher than the diesel fuel. To increase the performance some suitable additives also find out the exhaust gas decrease NOx EGR is also adopted to conduct the above tests are performed with varying percentage of EGR and it has been found that NOx decreases at the same time the engine performance was decreased.

\section{INTRODUCTION}

Palm oil and other oils having the comparable energy density, cetane number, heat of vaporization and stoichiometric air fuel ratio to diesel oil. But using these oils directly in the diesel engines due to various operational and durability of the engine problems such as malfunctioning of fuel pump, sticking of piston rings poor atomization of fuel cold starting trouble etc. High viscosity and low volatility and poly unsaturated nature of the straight using of these oil fuels with its blends causing all the above problems. Therefore it is suggested to enhance these properties of these fuels before using as the fuel in this diesel engine. Transesterification is an effective process to overcome these problem associated with these palm and other oils and its associated blends. It is a reversible reaction of triglyceride (oil) with alcohol to form esters and glycerol. To improve rate of reaction and its suitability for a fuel to diesel, and additives/catalyst is to be used then it is converted as a suitable oils called the biodiesel. This fuel has superior fuel properties when compared to straight palm oil. The biodiesel is a renewable fuel and is free from sulphur and other aromatic compounds. The biodiesel of these palm oil is having a closed carbon cycle it does not burden the environment with $\mathrm{CO}_{2}$ emission. Generally diesel engine produces the less carbon monoxide, and unburned hydrocarbon and particulate emissions when run on biodiesel compared to conventional diesel fuel. Several attempts were made by many researchers to analyze the 
characteristics C.I engine fuelled with biodiesel derived from different alternative fuels like Palm oil ethanol, Methanol, vegetable oils, rap seed oils, etc,(Nwafor, 2004; Ramdhas et al,2005; Nabi et al, 2006;Rao et al, 2006) these investigations showed that the esters of the above oils provide better performance and reduced emissions than the other alternative oils. However the increased NOx emissions are reported with biodiesel compared to diesel, the alternative oils and other alternative fuels like palm and rap seed oil plants etc, growing in many more countries like Thailand, Malaysia and other third developing countries is leading to increase the interest of these alternative oils. These oils are mixed with ester as a substitute for diesel in that part of the Countries. The recognized technique for attaining lower NOx emission levels on diesel engines is the Exhaust Gas Recirculation (EGR) the reason for reduction in NOx emission using EGR in diesel engines are reduced oxygen concentration and decreased peak cylinder temperature.

A. Use of Palm Oil as a Blend with Diesel Fuel in the Hot Surface Ignition Engine

Many researchers have been investigating on the use of vegetable oils in a compression ignition engine. Since they do not contain aromatic hydrocarbons, sulphur , metals the problem of acid rains and crank case dilution are eliminated. On the other hand high viscosity of palm oil reduces the fuel atomization and increased fuel spray penetration. Hence the parts of the fuel which is deposited on the walls may not ignite and is responsible for the information of engine deposits. In the hot surface Ignition engine, If the ignition of the fuel takes place in the combustion chamber due to hot surface, then it is called hot surface ignition engine. The hot surface ignition method is used in C.I. Engines, for the fuels like alternative. The function of the hot surface is to provide favorable local ignition condition, followed by flame propagating through the fuel air mixture to establish a stable diffusion flame. Surface Ignition occurs when the temperature of the air-fuel mixture adjacent to the hot surface exceeds its self ignition limit. The minimum surface temperature needed for this kind of ignition depends on both physical and chemical properties of the fuel to be ignited and the operating conditions prevailing inside the combustion chamber.
There Are Many Techniques By Which The Alternate Fuel Can Be Used As A Fuel In Hot Surface ignition Engines As Reported By Engine Ecklund Et Al [1996]. The techniques are

- Solution

- Fumigation

- Dual injection

- Spark ignition

- Ignition improvers

- Surface ignition

The Hot surface-It is provided by concentrating accumulating the heat of combustion at a position on the piston top or by supplying external energy to the heating elements inside the combustion chamber. The hot surface ignition is making use of the a ceramic material of the partial stabilized zirconium plate which is weld in side of the cylinder chamber of the engine which will be connected through the electric connection and from that the hot surface will become in to red hot condition there by igniting the automized level of the fuel in the top portion of the cylinder and propagate the flame in to entire cylinder. Which is a new concept as it is being used in the alcohols as fuels in I.C. Engines to over come diesel fuel replacement. The Hot surface material is initially heated by applying a voltage (typically $1.5 \mathrm{volts}$ ) to it. This is to cause it to become red hot condition so as to ignite the fuel at compression and starts the internal combustion cycle. Once the cycle has started, the power source can be disconnected, as with the heat generated at combustion the CATALYTIC Reaction generated between the methanol and platinum in the plug coils becomes sufficient ti keep the process going. The catalytic reaction is a reaction whereby platinum will glow in the presence of methyl alcohol vapor. This will happen without any external power source begin applied.

The Ceramic Material Hot Surface Ignition MethodBA ceramic material (partial Stabilized Zirconia) is weld inside the top portion of the cylinder chamber. It is connected to the Electric Circuit, So that the ceramic surface maintained the hot surface to ignite the fuel the fuel mixture 


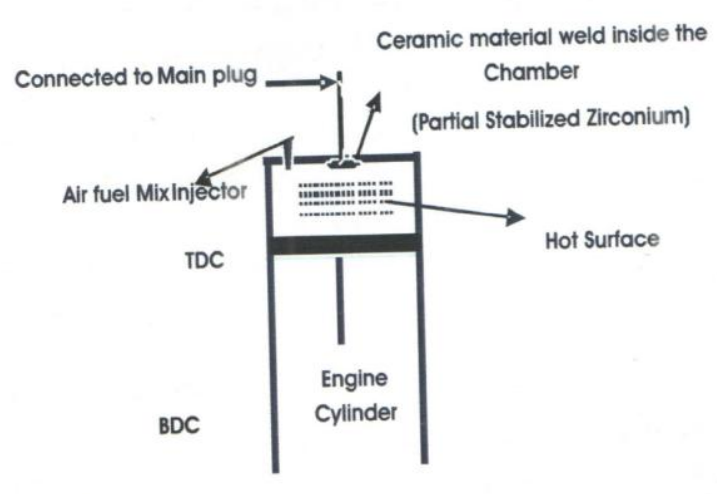

Fig. 1.Operation Engine Cylinder

\section{THE TYPE OF INJECTION SYSTEM USED}

The piezoelectric injection technology CORA 2 system which is used in this hot surface ignition engine has changed dramatically, ever tightening emission standards and also need for the fuel economy. The direct injection engines with full electronic injection timing control, with excellent atomization and specific formation of fuel spray in a very short time. This can only be achieved by high-precision injections with very short transition time and stabilized pressure control. The injection system development is also characterized by its efforts to reduce combustion noise significantly, in this the piezoelectric technology was introduced by the FEV pilot injection system which can be better stabilized with piezoelectric actuators rather than conventional solenoid driven valves. The outstanding rate shaping capabilities of the piezoelectric spill valves have been used widely: spilling only part of the pump capacity can be achieved by keeping the valve stable in any open position. Again, the piezoelectric technology facilitates a more stable pilot injection and serves as a tool to investigate rate shaping effects in combustion. The piezoelectric injector CORA 2 has also been adapted to methanol or ethanol injection. Due to its fuel saving potential, direct injection is increasingly applied also to gasoline combustion engines. The Gasoline combustion engines require, however, a different injection system than that of diesel engines. To this end, FEV has developed an air assisted injector, featuring excellent atomization for direct injection. With this injector, it has been demonstrated that homogeneous internal mixture formation facilitates with low emissions.

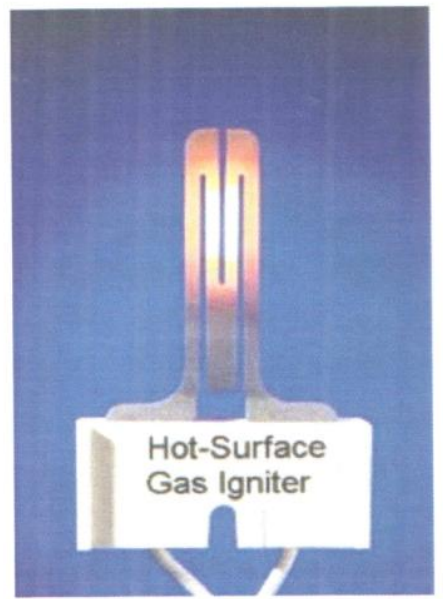

Fig. 2.Shows Hot surface Gas Igniter

\section{A. Objectives of This Experiment}

- By using the Alternative fuel like palm oil and its different blends with diesel oils, it is used in hot surface ignition engine for replacement for Diesel Fuel.

- Modifying the C.I. Engine as hot surface ignition engine by suitable material is welded in side of the engine cylinder chamber, as it can be used as hot surface ignition engine, and used the palm oil with $20 / 25 / 30 / 40 / 50 \%$ blends with diesel as the alternative fuels with suitable additives the same results are comparing with diesel fuel results.

- Observing and analyzing the engine performance on characteristics like BHP (Break Horse Power), IMP (Indicated Horse Power), Indicated thermal efficiency, Break thermal efficiency. Specific Fuel Consumption, and Total Fuel Consumption.

- Experimental investigations on hot surface ignition by providing different catalytic coating to combustion chamber with an objective to find the best one in terms of performance, Exhaust emissions and combustion parameters.

- Testing of the catalytic coatings like copper coating, Aluminum Oxide coating, Chromium Oxide coating, Magnesium Oxide coating etc, showing the best performance in hot surface ignition engine.

- By using different additives like Iso-Amyl Nitrate, Tri-Ethelyne Glycol Di Nitrate Ethylene Glycol, Cyclo hexyl nitrate with Alternative fuels like palm 
oil and various operating parameters can also be studied.

- There by observing the exhaust emissions ( by Exh. Measu.Meter) like $\mathrm{HC}, \mathrm{CO}, \mathrm{NO}, \mathrm{NO} 2$, Smoke emissions (by Bosch Smoke Meter), Particulate Emissions.

- And finally compare the above results with diesel as fuel in C.I. Engine.

- Points are to be observed while using an alternative blends as fuel in hot surface ignition engine.

- Ignition characteristics of alternative fuel, injection timing, position and length of hot surface material, Hot Surface temperature and water content in alternative fuel .

- Engine speed, fuel injection timing and position of the glow plugs have a strong effect on the ignition characteristics.

- Combustion difficulties appear as the load decreases, making idling impossible.

- Find out hot surface temperature for proper ignition and other systems.

- Brake thermal efficiency is comparable to that of diesel.

- Higher / Lower carbon monoxide and hydrocarbon emissions.

- Larger / Smaller reduction in NOx emissions.

- Shoot or free combustion

- Quieter / tough operation procedures.

- Longer / smaller Ignition delay.

\section{EXPERIMENTAL SETUP}

Fig:3 shoes A single cylinder, vertical , 4 stroke water cooled, electrically loaded 5HP S.P.Engineer=s engine was selected. The pressure, temperature and the time for $50^{\circ} \mathrm{cc}$ of fuel consumption, the selected fuel inlet temperature, the lubricant oil temperature, intake air and exhaust gas temperatures etc. are parameters measured during the experimentation. First the diesel fuel was used to start the engine and then switched over to palm oil blends of the fuel and note the results After the test is over with the palm oil blends again switched back to diesel to avoid problems with palm oil, it is heated to $80^{\circ} \mathrm{C}$ Before the fuel pump and fuel injector . This will made the smooth flow of this oil into the engine. Two different fuel tanks were used in the experimentation. One for diesel fuel and the other for palm oil blend. Diesel used for starting the engine and for stopping the engine. Here suitable additives also added for better performance of the engine. For reducing the NOx emissions exhaust gas recirculation system also provided for better combustion process.

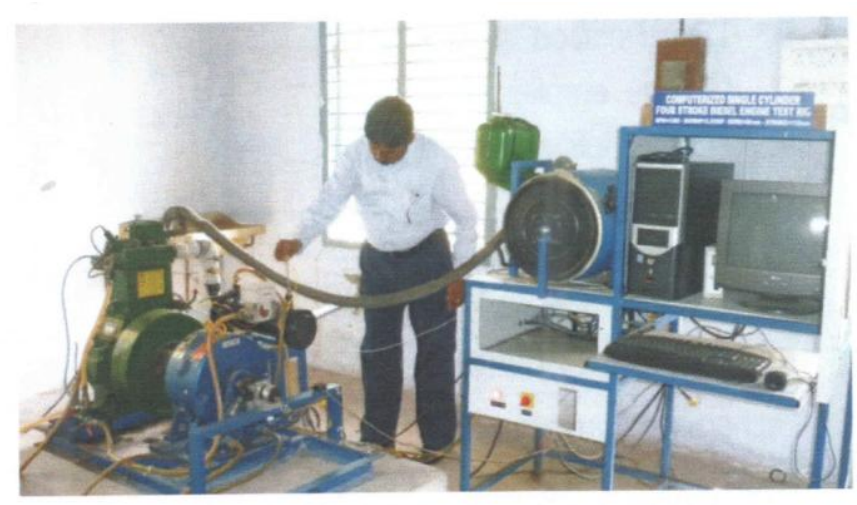

Fig. 3.Computerized single cylinder four stroke diesel engine.

The engine test was conducted at a rated speed at $1500 \mathrm{rpm}$ by varying the electrical load. The experiment was repeated twice at each load and the readingswere taken at half an hour after changing the load. Infrared analyzer was used to analyze emissions of carbon monoxide and unburned hydrocarbons. Nox emissions estimated by the use of chemiliuminescence analyzer . The analyzers were switched on much before the commencement of the test.

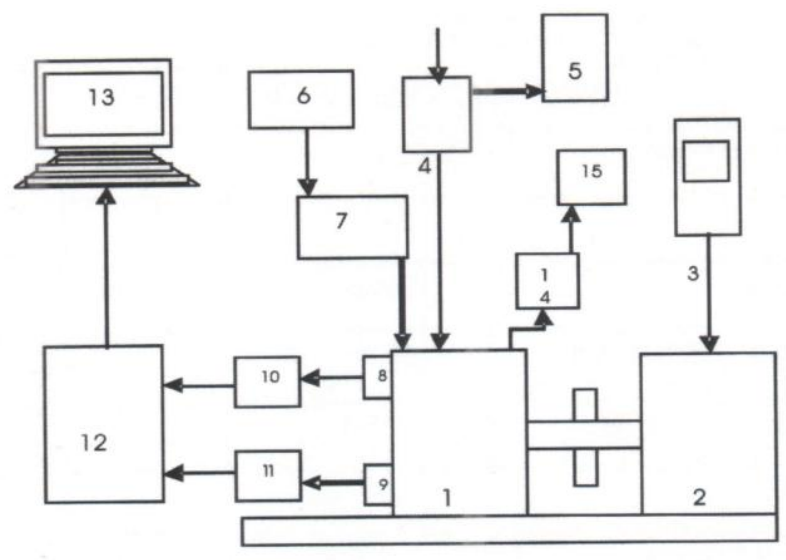

Fig. 4.Shows the Schematic diagram of the Experimental setup
A. The main components of the Single Cylinder Four Stroke Diesel Engine

1. Diesel Engine 
2. Electric Dynamometer

3. Dynamometer Control

4. Air Box

5. U.Tube manometer

6. Fuel tank

7. Fuel Flow Meter

8. Pressure Transducer

9. TDC Position sensor

10. Charge amplifier

11. TDC amplifier circuit

12. A/D Card

13. Personal computer

14. Exhaust gas amplifier

15. AVL Smoke meter

A schematic diagram of the engine test rig is shown in fig: 2 and its specifications are given in below. A swinging field electrical dynamometer was used to apply the load on the engine. This electrical dynamometer consists of a 5KVA AC alternator (220V, 1500rpm) mounted ion the bearings and on the rigid frame for the swinging field type of loading. The output power is directly obtained by measuring the reaction torque. Reaction force (torque) is measured by a strain gauge type load cell for accuracy. A water rheostat with an adjustable depth of immersion electrode is provided to dissipate the power generated. A panel board consisting of ammeter, voltmeter, switched and fuse, load cell indicator, digital rpm readout etc, is also provided. The properties of diesel and $25 \%$ POME is given below.

Table 1. SPECIFICATIONS OF THE ENGINE

\begin{tabular}{|c|c|}
\hline Manufacture & Engineer's Diesel Engine \\
\hline Model & TAF -1 \\
\hline Type & Direct injection, air cooled \\
\hline Bore x stroke $(\mathrm{mm})$ & $87.5 \times 100$ \\
\hline Compression Ratio & $17.5: 1$ \\
\hline Cubic capacity & 0.662 lit \\
\hline Rated Power & $4.4 \mathrm{KW}$ \\
\hline Rated Speed & $1500 \mathrm{rpm}$ \\
\hline Start of Injection & $23.4^{\circ} \mathrm{b}$ TDC \\
\hline Connecting rod length & $220 \mathrm{~mm}$ \\
\hline Injector operating pressure & $200 \mathrm{~B} 205 \mathrm{bar}$ \\
\hline
\end{tabular}

Different graphs are plotted based on the experimental results and the same results compared with the diesel fuel results in the form of graphical representations

The fig: 5 shows The variation of exhaust gas temperature with engine load, slightly higher exhaust temperature was observed with the Palm oil for the entire load range of the engine.

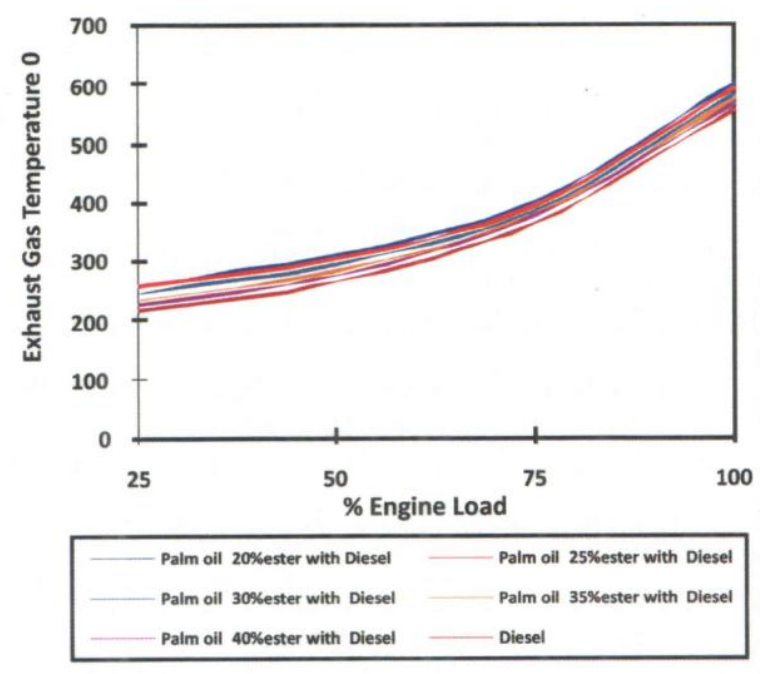

Fig. 5.shows variation of Exhaust gas temperature

The fig:6 shows The variation of specific fuel consumption with the engine, slightly higher fuel consumption was observed with the palm oil for the entire load range as the calorific value is slightly low consequently more amount of oil was inducted in to the engine .

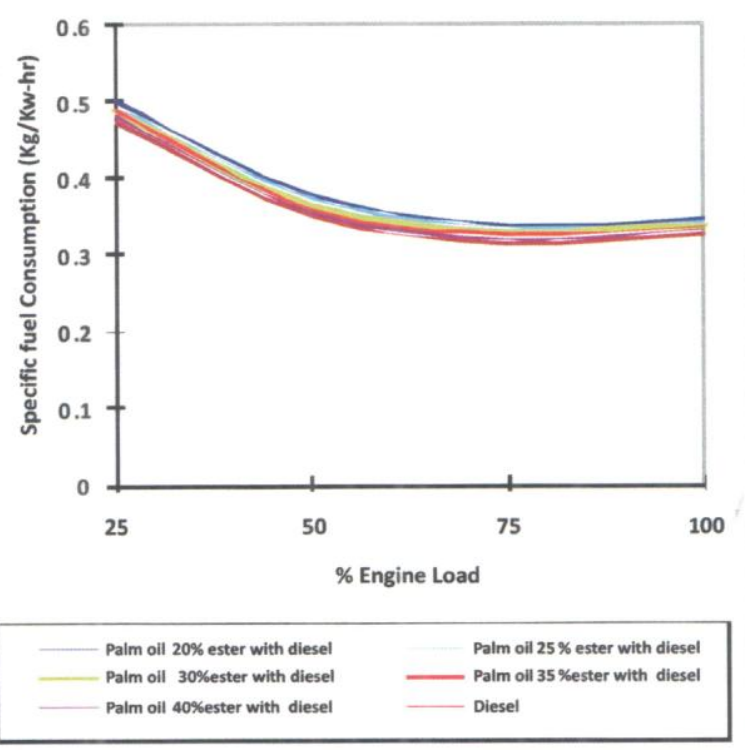

Fig. 6.Comparison of Specific Fuel 
The fig: 7 Shows the (co) carbon monoxide emissions of palm oil were compared with diesel the carbon monoxide emissions found to be significantly higher with the oil than diesel.

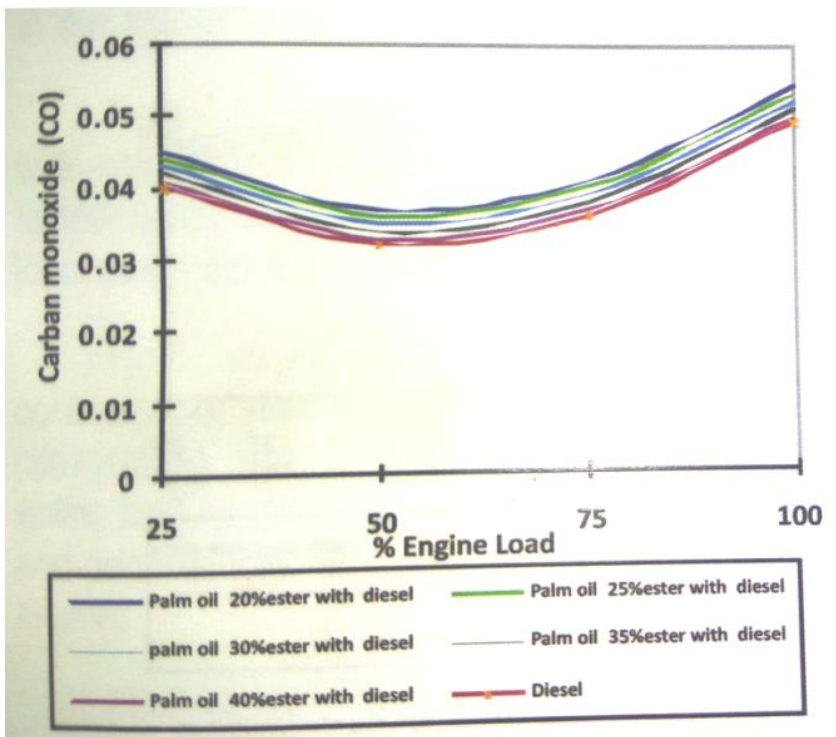

Fig. 7.Variation of Carbon monoxide Emission

The fig: 8 Shows the variation of the HC hydrocarbons with the rich mixtures of palm oil with diesel mixture at higher engine loads and due to non-availability of oxygen, hydro carbon emissions for palm oil mixture, was higher as compared with diesel.

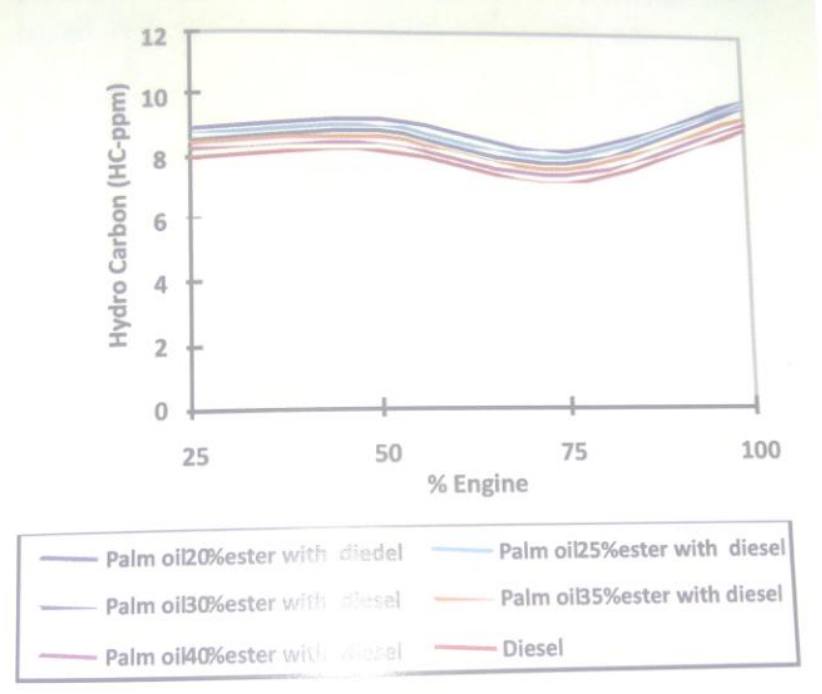

Fig. 8.

The fig: 9 Shows the variation of COsubb2 emissions with the engine load. These emissions were found to be higher with palm oil at nearby full load. However there is not much of a difference in the both the fuels up to $50 \%$ of engine load.
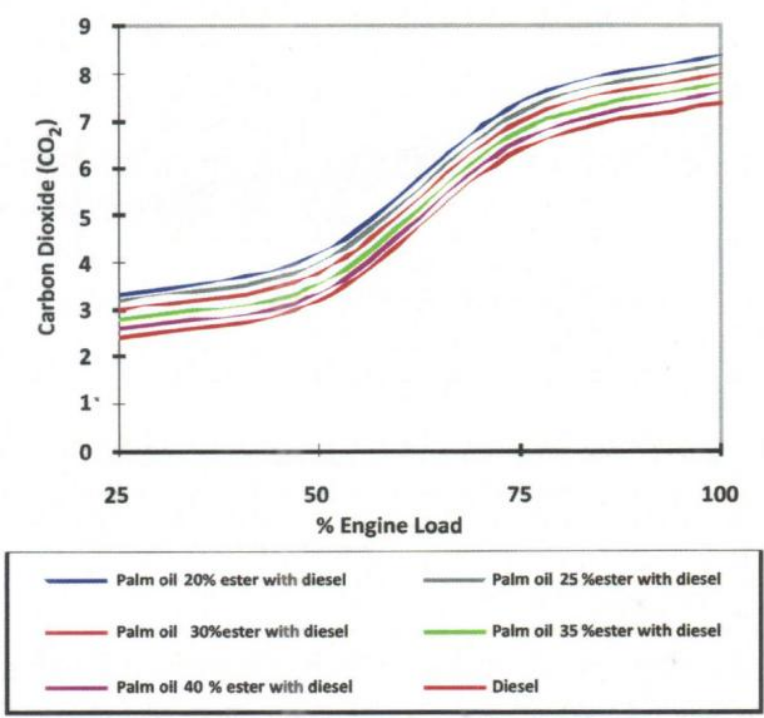

Fig. 9.Variation of Corbon oxide

The Fig: 10 Shows the NOx emissions against engine load. These are higher by $200 \mathrm{ppm}$ at full load with the palm oil. Availability of oxygen and high burned gas temperature are the reasons for the formation of higher NOx emissions with the diesel fuel. However these emissions are significantly low with palm oil the burned gas temperature are lower. NOx emissions for diesel fuel to be maximum at $100 \%$ of the engine load.

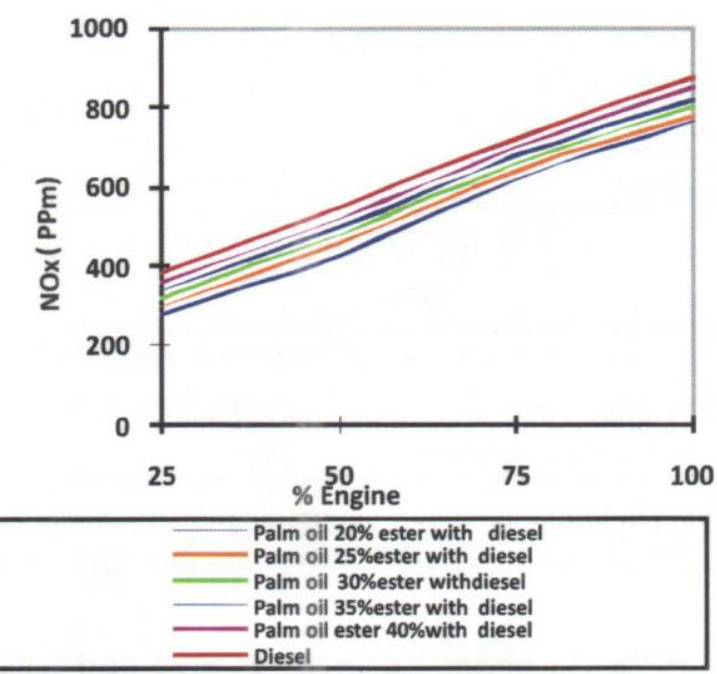

Fig. 10.Shows Variation of NOx

The Fig: 11 the variation of the Brake thermal efficiency with EGR at rated loads. 

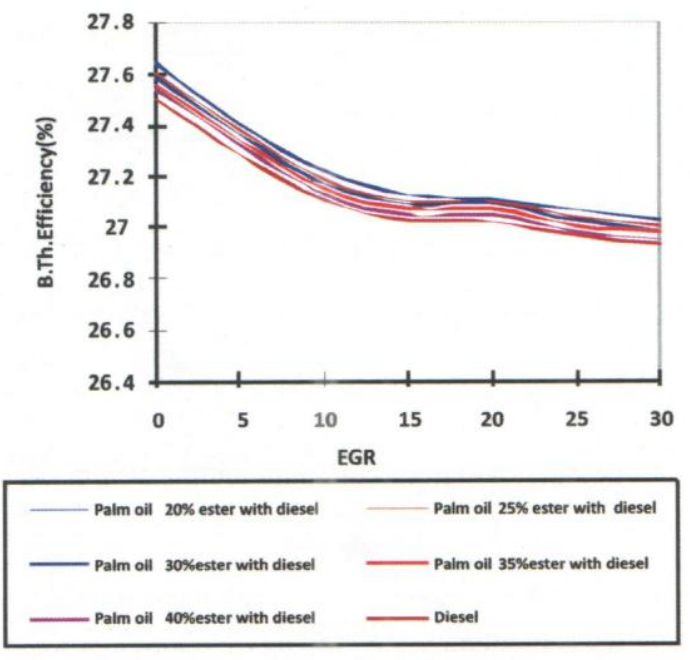

Fig. 11.

The Fig:12 Shows the unburned hydro carbon emission for diesel and different $\%$ of palm oil blends with percentage of EGR at related load. It is observed that UBHC emission increase in EGR \% for diesel and related POME blends. The $\mathrm{O} 2$ molecules in the blended fuel will take part in combustion this may be the possible reason for lower UHBC emission.
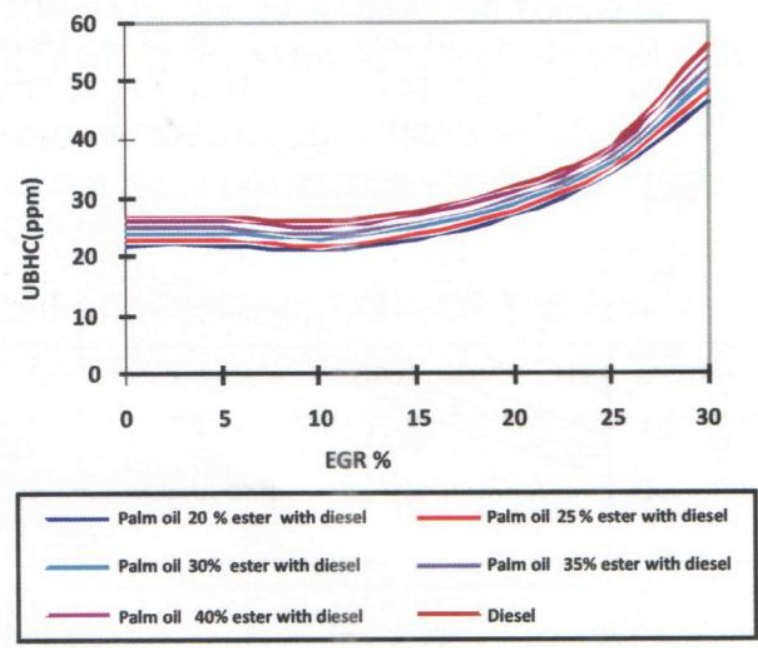

Fig. 12.

The fig:13 Shows the effect of EGR on the $\mathrm{CO}$ emission for diesel and 25\% POME at rated load. Co emission for increase in EGR percentage for both diesel and 25\% POME. The $\mathrm{CO}$ emission is lower for the above mixture of palm oil compared to diesel. The possible reason may be lower excess oxygen available for compulsion due to EGR, which results in decrease in air fuel ratio. The reason for lower $\mathrm{CO}$ emission for the above mixture of palm oil is due to the presence of inherent oxygen.

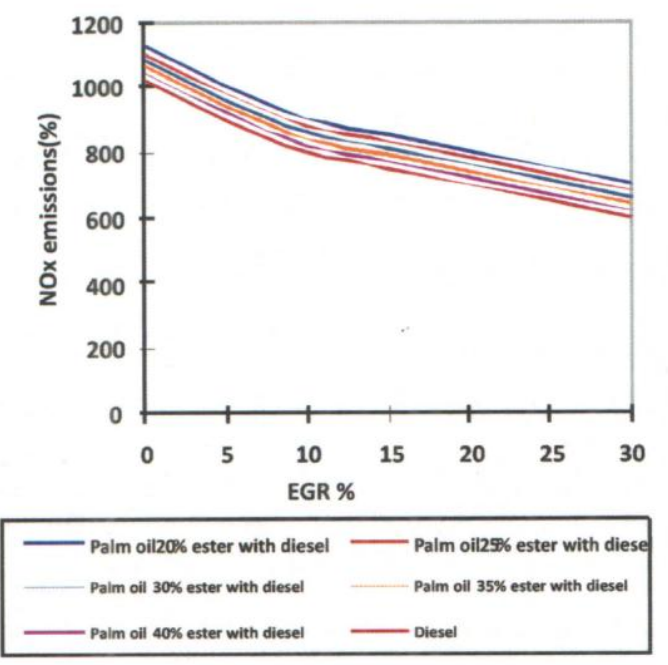

Fig. 13.

The fig:14 Shows variation of NOx emissions with percentage of EGR at rated load. It is Noted that NOx emissions reduces with increase in percentage of EGR as expected. This is due to reduction in excess $\mathrm{O} 2$ content at the time of combustion in the cylinder of EGR.
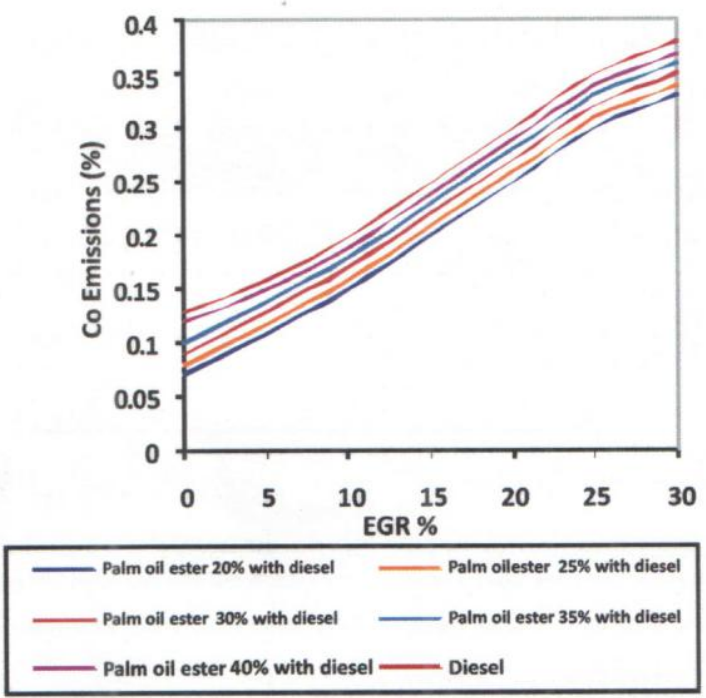

Fig. 14.

The recognized technique for attaining lower NOx emission levels on diesel engines is the exhaust gas recirculation EGR the reason for reduction in Nox emission during EGR in diesel engines are reduced oxygen concentration and decreased peak cylinder temperature. 


\section{RESULTS AND DISCUSSION}

After conducting tests on the engine the results were processed and they are presented in the form of graphs variation of exhaust gas temperature is shown in the figures.

Fig.5 Higher exhaust temperature is observed with palm oil due to higher ignition delay. Exhaust temperatures are found to be higher throughout the load range compared to diesel.

Fig. 6 shows the variation of specific fuel consumption with engine load, slightly higher fuel consumption was observed with the palm oil for the entire load range as the calorific value is slightly low and consequently more amount of oil was inducted into engine.

Fig.7 carbon monoxide emissions of palm oil were compared with diesel in carbon monoxide emissions found to be higher with the oil than diesel, with rich mixtures of higher engine loads and due to non availability of oxygen, CO emissions were higher and the same can be observed from the figure.

Fig.8 unburnt hydrocarbon emissions from palm oil, diesel were shown in the fig. These emissions were higher with palm oil compared with diesel.

Fig.9. variation of $\mathrm{CO} 2$ emissions with engine load is shown in the fig emissions were found to be higher with palm oil and nearly full load. However there is not much of a difference in the emissions of both the fuels up to $50 \%$ of the engine load. NOx emissions were shown against the engine load.

Fig.10. These are higher by $200 \mathrm{ppm}$ at full load with palm oil. Availability of oxygen and high burned gas temperatures are the reasons for formation of higher NOx emissions with the diesel fuel. However these emissions are significantly low with the palm oil the burned gas temperatures are lower. NOx emissions for diesel fuel to be maximum at $100 \%$ of the engines load.

Fig.11. The variation of the brake thermal efficiency with EGR at rated loads

Fig.12. shows the unburned hydro carbon emission for diesel and different $\%$ of palm oil blends with percentage of EGR at related load. It is observed that UBHC emission increase in EGR \% for diesel and related POME blends. The $\mathrm{O}_{2}$ molecules in the blended fuel will take part in combustion this may be the possible reason for lower UHBC emission
Fig.13 shows the effect of EGR on the CO emission for diesel and 25\% POME at rated load. Co emission increase in EGR percentage for both diesel and 25\% POME. the CO emission is lower for the above mixture of palm oil compared to diesel. The possible reason may be lower excess oxygen available for combustion due to EGR, which results in decrease in air fuel ratio. The reason for lower $\mathrm{CO}$ emission for the above mixture of palm oil is due to the presence of inherent oxygen.

Fig.14 shows variation of NOx emissions with percentage of EGR at rated load.it is noted that NOx emissions reduces with increase in percentage of EGR as expected. This is due to reduction in excess $\mathrm{O}_{2}$ content at the time of combustion in the cylinder because of $E G R$

\section{CONCLUSION}

(i.) Performance of palm oil fuelled engine is comparable with diesel fuelled engine.

(ii.) Since the exhaust emission of palm oil is slightly higher than diesel. Therefore, palm oil fuel can be thought of a better alternative for the diesel engine.

(iii.) Carbon deposits, fuel filtering problems, lubricating oil dilution are still persisting even after its heating to 80 $\mathrm{C}$, heater input is subtracted for calculation of brake power of engine.

(iv.) To find out emission characteristics of the vegetable oils, 100 hours duration test have to be conducted.

(v.) Further heating of the palm oil in steps of $25 \mathrm{C}$ can be attempted to find out optimum heating of the oil.

\section{REFERENCES}

[1]. G.R,Quick, 1980, "Development in use of vegetable oils as fuel for diesel engine". ASAE papers NO. 80, P.1525-1529

[2]. C.L.Peterson, G.I.. Wagner and D.L, Audd, 1983, "vegetable oil substitutes for diesel fuel", Trans.ASAE 26 (1-4), PP 322-327

[3]. Goetilen HZ Zieowsld M, Kanfanan KR, Pratt GL, 1985 "A Fuel injection anomlies observed during long burn engine performance tes on alternate fuels".SAE Technical paper series no. 852089 ,Society of automotive Engineers, Ivlsa, Oklahoma.

[4]. Rao,P.S., GopalaKrishan,K.V., 1989, "A Use of non-edible vegetable oils as diesel engine fuels". Jouranl of the institution of Engineers, Vol.70, No.4, 
[5]. Insigigar A, Karaomangolu, F.AksoyHA, Hamdullahpur F. GulderLO, 1994. "A Performance and emission characteristics of a diesel engine operating on sunflower seed oil methyl ester". Ap BiocheMelotechnol, 45/46:93102

[6]. SapvanS.M.Nasjuki, H.H.Azlan, 1996. A Use of palm oil as diesel fuel substitute, Proceedings of the Institution of Mechanical Engineers, part B A, Journals of power and Energy, Vol.210, NI.P.P. 47-53

[7]. Mittelbach M 1996, "A Diesel Derived from Vegetable Oils", VI: Specifications and quality control of iodiesel, BioresourTechnol 56:7-11

[8]. da Costa, R.E.and Lora E. E.L., 2006. The energy balanced in the productions of palm oil biodiesel-two case studies :Brazil and Colombia. Proceedings of world Bioenergy and pellets.http://www.syebio.se/attachments /33/295.pdf.

[9]. Masjuki, H., Abdulmuin, M.Z.andSil, H.S., 1996.Indirect injection diesel engine Operation on palm oil methl esters and its emulsions, Proce..Instn.Mech.Engrs., part D:Journal of Automobile Engineering, 211, 291-299
[10]. Nabi, M.N.,Akhter, M.S.andShahadat, M.M.Z., 2006.Impro vement of engine emission with conventional diesel fuel and diesel oil- biodiesel blends. BioresourseTechnology , $97,372-378$

[11]. Nwafor, O.M.I., 2004 Emission on rapeseed methyl ester. Renewable energy, 29. 119-129

[12]. Rakopoulos, C.D.Antonopoulos, K.A.,Rakopoulos, D.C. Hountalas, D.T.and Giakoumis, E.G., 2006. Comparative performance and emissions study of a direct injection Diesel engine using blends of Diesel fuel with vegetable oils or bio $\mathrm{B}$ diesels of various origins. Energy conversion and management, 47 .3272-3287.

[13]. Ramadhas A.S., Jayaraj.S .and Muraleedharan C.,2005. Performance and emission evaluation of a diesel engine fueled with methyl esters of rubber seed oil. Renewable Energy. 30, 1789-2000.

[14]. Rao G.L.N.Sravanan, S.Sampath, and Rajagopal.K, 2006, Emission characteristics of a direct injection Diesel Engine fuelled with Bio-diesel and its Blends. Proceedings of the A International System Allied publishers private limited. India, 353-356 